\title{
Effect of milk centrifugation and incorporation of high heat-treated centrifugate on the microbial composition and levels of volatile organic compounds of Maasdam cheese
}

\author{
Prabin Lamichhane, ${ }^{*} \dagger$ Anna Pietrzyk, ${ }^{*} \ddagger$ Conor Feehily, ${ }^{*} \S$ Paul D. Cotter, ${ }^{\star} \S$ David T. Mannion, ${ }^{*}$ \\ Kieran N. Kilcawley,* Alan L. Kelly, $†$ and Jeremiah J. Sheehan*1 \\ *Teagasc Food Research Centre, Moorepark, Fermoy, Cork, Ireland P61 C996 \\ †School of Food and Nutritional Sciences, University College Cork, Cork, Ireland T12 YN60 \\ ¥School of Microbiology, University College Cork, Cork, Ireland T12 YT20 \\ §APC Microbiome Ireland, University College Cork, Cork, Ireland T12 YT20
}

\begin{abstract}
Centrifugation is a common milk pretreatment method for removal of Clostridium spores which, on germination, can produce high levels of butyric acid and gas, resulting in rancid, gassy cheese. The aim of this study was to determine the effect of centrifugation of milk, as well as incorporation of high heat-treated centrifugate into cheese milk, on the microbial and volatile profile of Maasdam cheese. To facilitate this, 16S rRNA amplicon sequencing in combination with a selective media-based approach were used to study the microbial composition of cheese during maturation, and volatile organic compounds within the cheese matrix were analyzed by HPLC and solid-phase microextraction coupled with gas chromatography-mass spectrometry. Both culture-based and molecular approaches revealed major differences in microbial populations within the cheese matrix before and after warm room ripening. During warm room ripening, an increase in counts of propionic acid bacteria (by $\sim 10^{1.5} \mathrm{cfu}$ ) and nonstarter lactic acid bacteria (by $\sim 10^{8} \mathrm{cfu}$ ) and a decrease in the counts of Lactobacillus helveticus (by $\sim 10^{2.5} \mathrm{cfu}$ ) were observed. Lactococcus species dominated the curd population throughout ripening, followed by Lactobacillus, Propionibacterium, and Leuconostoc, and the relative abundance of these accounted for more than $99 \%$ of the total genera, as revealed by high-throughput sequencing. Among subdominant microflora, the overall relative abundance of Clostridium sensu stricto was lower in cheeses made from centrifuged milk than control cheeses, which coincided with lower levels of butyric acid. Centrifugation as well as incorporation of high heat-treated centrifugate into cheese milk
\end{abstract}

Received November 22, 2017.

Accepted January 26, 2018.

${ }^{1}$ Corresponding author: Diarmuid.Sheehan@teagasc.ie seemed to have little effect on the volatile profile of Maasdam cheese, except for butyric acid levels. Overall, this study suggests that centrifugation of milk before cheesemaking is a suitable method for controlling undesirable butyric acid fermentation without significantly altering the levels of other volatile organic compounds of Maasdam cheese.

Key words: centrifugation, microbial composition, high-throughput sequencing, volatile profile, Maasdam cheese

\section{INTRODUCTION}

Centrifugation at $\sim 9,000 \times g$ is a milk pretreatment method for removal of Clostridium spores. Some species of Clostridium, on germination, can produce gas and a high level of butyric acid via butyric acid fermentation, resulting in rancid, gassy cheeses (Su and Ingham, 2000; Le Bourhis et al., 2007). As well as removal of bacterial spores, centrifugation removes indigenous bacterial cells present in milk (Te Giffel and Van Der Horst, 2004). Some of these indigenous milk microorganisms can survive pasteurization and can grow during ripening of cheese (Grappin and Beuvier, 1997; Jordan and Cogan, 1999; Quigley et al., 2013; Sheehan, 2013). Therefore, it may be assumed that the reduction in microbial load in cheese milk by centrifugation may influence the microbial composition of cheese during maturation, as the environment would be less competitive, thus further favoring the growth of the most abundant bacteria. The microbial composition within the cheese matrix is known to play an important role in determining biochemical and ripening characteristics, including flavor development through production of enzymes and metabolites, of different varieties of cheese (Beuvier et al., 1997; Beresford et al., 2001; Montel et al., 2014; Guarrasi et al., 2017).

Although traditional culture-based approaches are effective for quantifying common starter or nonstarter 
bacteria, these approaches are not sensitive to those microorganisms that are difficult to culture, present as subdominant populations, or both (Quigley et al., 2013; O'Sullivan et al., 2015). Moreover, recent studies based on culture-independent approaches have suggested that some bacterial cells in a highly stressed condition are viable but not culturable (Quigley et al., 2013; Ruggirello et al., 2014; Hickey et al., 2018). Alternatively, molecular approaches, including high-throughput sequencing, can provide a detailed insight into the composition of both dominant and subdominant microflora. More recently, 16S rRNA amplicon sequencing has been increasingly used in the study of microbial composition within fermented food products, including cheese (Quigley et al., 2012; O'Sullivan et al., 2015; Alessandria et al., 2016). For the first time, we profiled the microbiota of cheese made from centrifuged milk, as well as cheese made from centrifuged milk containing high heat-treated (HHT) centrifugate compared with control cheeses, using high-throughput sequencing.

Maasdam is a washed-curd, brine-salted, large eyeforming, semihard cheese, which is developed by combining the cultures and technologies of Emmental and Gouda cheese. Apart from thermophilic lactobacilli, mesophilic mixed-strain cultures comprising Lactococcus and Leuconostoc are used as starters (as in Gouda cheese) and propionic acid bacteria (PAB) are used as secondary starters (as in Emmental cheese). To date, very little has been published regarding the microbial and volatile profile of Maasdam cheese, a better understanding of which will aid manufacturers to consistently achieve the desirable cheese aroma profile (Johnson and Lucey, 2006).

The objective of our study was to investigate the effect of (1) centrifugation and (2) the incorporation of the HHT centrifugate into cheese milk on microbial composition and levels of volatile organic compounds (VOC) of Maasdam cheese during maturation. In our study, centrifugation refers to the separation of bacteria and spores at a centrifugal force of $\sim 9,000 \times g$ (in some studies this is also referred as bactofugation; Te Giffel and Van Der Horst, 2004), whereas centrifugal separation refers to separation of milk into cream and skim milk. A parallel study was conducted investigating the effect of milk centrifugation and incorporation of HHT centrifugation on the composition, texture, and ripening characteristics of Maasdam cheese.

\section{MATERIALS AND METHODS}

\section{Cheese Manufacture}

Cheese milks were prepared as described by Lamichhane et al. (2018) and in Supplemental Figure S1 (https://doi.org/10.3168/jds.2017-14180). In summary, raw milk from a local dairy company (Dairygold Co Operative Society Limited, Cork, Ireland) was divided into 2 portions. One portion of the raw milk was separated into skim milk and cream using a cream separator. Control milk (CT) was prepared by adding a portion of cream and skim milk obtained from cream separator to achieve a protein to fat ratio of 1.13: 1 . Another portion of the raw milk was centrifuged at 9,000 $\times g\left(\right.$ at $50^{\circ} \mathrm{C}$ with flow rate of $1,000 \mathrm{~L} / \mathrm{h}$ ), resulting in centrifuged whole milk and centrifugate. Centrifuged whole milk was separated into cream and skim milk and high heat treatment $\left(120^{\circ} \mathrm{C}\right.$ for $\left.26 \mathrm{~s}\right)$ was applied to centrifugate. A second cheese milk type (i.e., centrifuged milk; CF) was prepared by adding a portion of cream and skim milk obtained from separation of centrifuged whole milk, and a third cheese milk type was prepared by mixing a portion of cream and skim milk obtained from separation of centrifuged whole milk and HHT centrifugate (CFHHT; at a level of 6 to 10\%, wt/ wt, depending on the protein content of centrifugate). The protein-to-fat ratio of all cheese milks were standardized to 1.13: 1. All cheese milks were pasteurized before Maasdam cheese manufacture. Maasdam cheeses were manufactured as per Lamichhane et al. (2018). Three experimental Maasdam cheese types [i.e., cheese made from control milk (CT cheese), centrifuged milk (CF cheese) and centrifuged milk containing HHT centrifugate (CFHHT cheese)] were each manufactured on 3 different occasions in replicate cheesemaking trials over a 3-mo period as per Lamichhane et al. (2018). Starters and secondary starters (frozen direct vat inoculate, Chr. Hansen Ltd., Cork, Ireland) used for the manufacture of Maasdam cheese were (1) mesophilic mixed-strain (C950, $18 \mathrm{mg} / \mathrm{kg}$ of milk), consisting of Lactococcus lactis ssp. cremoris, Lactococcus lactis ssp. lactis, and Leuconostoc; (2) Lactobacillus helveticus (LH-B01, $4.8 \mathrm{mg} / \mathrm{kg}$ of milk); and (3) PAB (PS-60, 7.0 $\mathrm{mg} / \mathrm{kg}$ of milk).

\section{Enumeration of Starter and Nonstarter Lactic Acid Bacteria and PAB}

Samples were aseptically removed from cheese wheels using a cheese trier at 1, 11, 41, 65, 97, 140, and $180 \mathrm{~d}$ of ripening. The cheese samples $(10 \mathrm{~g})$ were placed in a sterile stomacher bag (Grade, Leicestershire, UK), diluted (10-fold) with $2 \%$ (wt/vol) trisodium citrate buffer (VWR, Dublin, Ireland), and stomached for $10 \mathrm{~min}$ using a stomacher (Iul Instruments, Barcelona, Spain). Serial dilutions of 10 -fold diluted cheese samples were made using maximum recovery diluent, containing low levels of peptone $(1 \mathrm{~g} / \mathrm{L})$ and sodium chloride $(8.5$ $\mathrm{g} / \mathrm{L})$. Total numbers of nonstarter lactic acid bacteria 
(NSLAB) cells were enumerated on Lactobacillus selection agar (BD, Oxford, UK), with an overlay, after aerobic incubation for $5 \mathrm{~d}$ at $30^{\circ} \mathrm{C}$. Viable cells of $\mathrm{PAB}$ were enumerated on sodium lactate agar, supplemented with kanamycin sulfate (Sigma-Aldrich, Arklow, Ireland) at a level of $4 \mathrm{mg} / 100 \mathrm{~mL}$ of sodium lactate agar, after anaerobic incubation for $7 \mathrm{~d}$ at $30^{\circ} \mathrm{C}$, and only light brown colonies were counted as PAB (Rehn et al., 2011). Lactobacillus helveticus cells were enumerated on de Man, Rogosa, and Sharpe agar (BD) at pH 5.4 after anaerobic incubation for $3 \mathrm{~d}$ at $42^{\circ} \mathrm{C}$ (Hickey et al., 2017). Anaerobic conditions were maintained through the use of anaerobic gas jars and AnaeroGen system (Oxoid, Basingstoke, UK).

\section{Study of Microbial Composition Using High- Throughput Sequencing}

Sampling and Nucleic Acid Extraction. Aseptic samples were removed using a cheese trier, at 1, 11, $41,65,97$, and $180 \mathrm{~d}$ of ripening. Cheese samples ( $5 \mathrm{~g})$ were homogenized in $45 \mathrm{~mL}$ of Ringer's solution $(1 / 4$ strength, Sigma-Aldrich) in a stomacher (BagMixer 400P, Interscience, Saint Nom, France). Enzymatic lysis of homogenized cheese samples was conducted before DNA extraction and included treatment with lysozyme (1 mg/mL, EC 3.2.1.17, Sigma-Aldrich) and proteinase K (5 mg/mL, EC 3.4.21.64, Sigma-Aldrich), followed by incubation at $37^{\circ} \mathrm{C}$ for $30 \mathrm{~min}$ and $55^{\circ} \mathrm{C}$ for 15 min, respectively. The DNA was extracted using the PowerFood Microbial DNA Isolation Kit (MoBio Laboratories Inc., Carlsbad, CA).

PCR Amplification of the Microbial $16 S$ $\boldsymbol{r R N A}$ Gene. Extracted DNA was amplified using primers targeting the $\mathrm{V} 3$ and $\mathrm{V} 4$ regions of the bacterial 16S rRNA gene. Illumina (San Diego, CA) adapter overhang nucleotide sequences were added to the primers. Therefore, the primer set used included the $16 \mathrm{~S}$ amplicon PCR forward primer (5'-TCGTCGGCAGCGTCAGATGTGTATAAGAGACAGCCTACGGGNGGCWGCAG) and the $16 \mathrm{~S}$ amplicon PCR reverse primer (5'-GTCTCGTGGGCTCGGAGATGTGTAAGAGACAGGACTACHVGGGTATCTAATCC). Identification of individual sequences from the pooled samples was achieved by incorporating a dual indexing strategy, where 2 unique pairs of 8 base indices were attached to each sample. Prepared samples were purified by using AMPure XP purification system (Beckman Coulter, Takeley, UK) before sequencing.

Amplicon PCR reactions contained $25 \mu \mathrm{L}$ of $2 \times$ KAPA HiFi HotStart ReadyMix (Roche Diagnostics, West Sussex, UK), $10 \mu \mathrm{L}$ of each of the primers, and 5 $\mu \mathrm{L}$ of the DNA template. Therefore, the total volume of the reaction mix was $50 \mu \mathrm{L}$. The PCR amplification was carried out using a 2720 Thermal Cycler (Applied Biosystems, Foster City, CA). The amplification parameters were initial denaturation at $95^{\circ} \mathrm{C}$ for $3 \mathrm{~min}$, followed by 30 cycles consisting of three 30 -s steps including denaturation at $95^{\circ} \mathrm{C}$, annealing at $55^{\circ} \mathrm{C}$, and extension at $72^{\circ} \mathrm{C}$. The process was completed by final elongation stage at $72^{\circ} \mathrm{C}$ for $2 \mathrm{~min}$. Obtained amplicons were quantified by using Quan-It dsDNA High Sensitivity Assay Kit (Invitrogen, Carlsbad, CA). Additionally, samples were normalized by dilution to equimolar concentrations before library preparation and sequencing.

High-Throughput Sequencing. The 16S rRNA amplicons from the V3 and V4 regions were sequenced on a MiSeq (Illumina, San Diego, CA) platform in the Teagasc sequencing facility, in accordance with standard Illumina sequencing protocols (document no. 15044223; https://www.illumina.com/content/dam/ illumina-marketing/documents/products/appnotes / 16S-Metagenomic-Library-Prep-Guide.pdf). Pairedend reads were assembled using FLASH (fast length adjustment of short reads to improve genome assemblies). Denoising, chimera detection, and clustering into operational taxonomic units were performed using USEARCH (Version 7.0-64 bit; http://www.drive5 .com/usearch/). Taxonomy was assigned using BLAST against the SILVA database release 123 (https://www .arb-silva.de/). Alpha diversity was calculated in QIIME (v1.9.0; http://qiime.org). Further data analysis was carried out using Phyloseq package in R (www.r -project.org).

\section{Analysis of Acetic, Propionic, and Butyric Acid}

Acetic, propionic, and butyric acids were recovered from cheese matrix by steam distillation and subsequently quantified by ligand exchange, ion-exclusion HPLC, as described by Kilcawley et al. (2001) with slight modification. Briefly, $5 \mathrm{~g}$ of grated cheese samples, $10 \mathrm{~mL}$ of $10 \%$ (wt/vol) $\mathrm{H}_{2} \mathrm{SO}_{4}$ (Sigma-Aldrich), $1 \mathrm{~mL}$ of valeric acid (Sigma-Aldrich) of concentration $1 \mathrm{mg} / \mathrm{mL}, 1$ drop of silicon antifoaming agent (SigmaAldrich), and $10 \mathrm{~mL}$ of distilled water were added to a distillation tube before distillation (2100 Kjeltec Distillation unit, Foss Analytic, Hillerød, Denmark). The first $100 \mathrm{~mL}$ of distillate was collected into a flask, mixed gently, and representative distillate samples were filtered using $0.2-\mu \mathrm{m}$ nylon syringe filters into HPLC vials (Agilent Technologies, Santa Clara, CA). Recovery of short-chain carboxylic acids from cheese matrix by steam distillation was checked based on recovery of valeric acid, which was added as an internal standard.

The filtered samples were then analyzed for acetic, propionic, and butyric acid content using HPLC (1260 Infinity, Agilient Technologies) equipped with Rezex 
RHM-Monosaccharide $\mathrm{H}^{+}(8 \%)$ column (Phenomenex, Cheshire, UK) under the following working conditions: sample injection volume, $40 \mu \mathrm{L}$; mobile phase, $0.01 \mathrm{~N}$ sulfuric acid (isocratic); flow rate, $0.7 \mathrm{~mL} / \mathrm{min}$; column temperature, $50^{\circ} \mathrm{C}$; run time, $50 \mathrm{~min}$; detection at 220 $\mathrm{nm}$ (UV detector). The quantification of analytes was based on the external standard method as described by Kilcawley et al. (2001). Results were expressed as milligrams per kilogram of cheese samples.

\section{Analysis of Volatiles}

Volatiles in cheese at $140 \mathrm{~d}$ of ripening were determined using GC-MS. Grated cheese samples $(4 \mathrm{~g})$ were placed in a $20-\mathrm{mL}$ screw capped amber solid-phase microextraction vial (Apex Scientific, Maynooth, Ireland) and equilibrated to $40^{\circ} \mathrm{C}$ for 10 min with pulsed agitation of $5 \mathrm{~s}$ at $500 \mathrm{rpm}$. Sample introduction was accomplished using a Shimadzu AOC 5000 Autosampler (Shimadzu Corporation, Kyoto, Japan). A single 50/30 $\mu \mathrm{m} \quad$ Carboxen/divinylbenzene/polydimethylsiloxane (Agilent Technologies) fiber was used. The solid-phase microextraction fiber was exposed to the headspace above the samples for $20 \mathrm{~min}$ at depth of $1 \mathrm{~cm}$ at $40^{\circ} \mathrm{C}$. The fiber was retracted and injected into the GC inlet and desorbed for $2 \mathrm{~min}$ at $250^{\circ} \mathrm{C}$. Injections were made on a Shimadzu 2010 Plus GC with an Agilent DB-624 UI $(60 \mathrm{~m} \times 0.32 \mathrm{~mm} \times 1.8 \mu \mathrm{m}$; Agilent Technologies, Cork, Ireland) column using a split/splitless injector with a 1/10 split. A Merlin microseal (Sigma-Aldrich) was used as the septum. The temperature of the column oven was set at $40^{\circ} \mathrm{C}$, held for $5 \mathrm{~min}$, increased at $5^{\circ} \mathrm{C} /$ min to $230^{\circ} \mathrm{C}$, then increased at $15^{\circ} \mathrm{C} / \mathrm{min}$ to $260^{\circ} \mathrm{C}$, yielding total GC run time of $50 \mathrm{~min}$. The carrier gas was helium held at a constant flow of $1.2 \mathrm{~mL} / \mathrm{min}$. The detector was a Shimadzu TQ8030 mass spectrometer detector (Mason Technology, Dublin, Ireland), run in single quadrupole. The ion source temperature was $220^{\circ} \mathrm{C}$ and the interface temperature was set at $260^{\circ} \mathrm{C}$. The MS mode was electronic ionization $(70 \mathrm{~V})$ with the mass range scanned between 35 and $250 \mathrm{amu}$. Compounds were identified using mass spectra comparisons to the NIST 2014 mass spectral library (https:// www.nist.gov/srd/nist-standard-reference-database -1a-v14), a commercial flavor and fragrance library (FFNSC 2, Shimadzu Corporation), and an in-house library created using authentic compounds with target and qualifier ions and linear retention indices for each compound. Linear retention indices were calculated as per Vandendool and Kratz (1963). Spectral deconvolution was also performed to confirm identification of compounds using an automated mass spectral deconvolution and identification system (AMDIS; http:// chemdata.nist.gov/dokuwiki/doku.php?id=chemdata: amdis). Batch processing of samples was carried out using metaMS (Wehrens et al., 2014). An autotune of the GC-MS was carried out before the analysis to ensure optimal GC-MS performance. All analyses were performed in triplicate.

\section{Statistical Analysis}

Three experimental cheese types (CT, CF, and CFHHT) were each manufactured on 3 different occasions in replicate cheese-making trials. An ANOVA, using IBM SPSS software version 24 (IBM Corp., 2016), was applied to determine the effect of treatment on formation of VOC. A split-plot design was used to determine the effect of treatment, ripening time, and their interactions on Lactobacillus helveticus, PAB, and NSLAB count and levels of short-chain carboxylic acids (acetate, propionate, and butyrate). Analysis for the split-plot design was carried out using the PROC MIXED procedure of SAS software version 9.3 (SAS Institute Inc., 2011). Tukey's multiple comparison test was used for paired comparison of treatment means at a $5 \%$ level of significance.

\section{RESULTS AND DISCUSSION}

\section{Cheese Composition}

The compositional parameters of cheeses were described in detail by Lamichhane et al. (2018) and in Supplemental Table S1 (https://doi.org/10.3168/jds .2017-14180). Briefly, except for levels of moisture in nonfat substances, all other compositional parameters of experimental cheeses were not statistically different. Cheeses made from cheese milk containing HHT centrifugate had higher $(P<0.05)$ levels of moisture in nonfat substances than cheeses made from centrifuged milk or control cheeses. This is attributed to the negative effect of HHT centrifugate (incorporated at levels of approximately 6 to $10 \%$ of the total cheese milk weight, depending on the protein content of centrifugate) on syneresis of rennet-induced milk gels. The mean moisture content of CFHHT cheese was $\sim 3 \%$ higher than that of $\mathrm{CT}$ and $\mathrm{CF}$ cheeses; however, the data were not differ statistically $(P=0.057)$.

\section{Growth and Viability of Lactobacillus helveticus, $P A B$, and NSLAB}

Mean viable counts of Lactobacillus helveticus in all experimental cheeses decreased $(P<0.001)$ from $\sim 10^{7} \mathrm{cfu} / \mathrm{g}$ at 1 and $11 \mathrm{~d}$ to $\sim 10^{4.5} \mathrm{cfu} / \mathrm{g}$ at $41 \mathrm{~d}$ (Figure $1 \mathrm{~A}$ ), indicating lysis during warm room ripening. Similar trends have previously been reported in Swiss- 
type cheese (White et al., 2003; Sheehan et al., 2008; O'Sullivan et al., 2016). As the increased number of NSLAB would influence the accuracy of Lactobacillus helveticus counts (O'Sullivan et al., 2016), we did not enumerate Lactobacillus helveticus beyond $41 \mathrm{~d}$. As expected, the mean viable count of PAB increased $(P$ $<0.001)$ in all experimental cheeses during the warm room ripening, from $\sim 10^{6.5} \mathrm{cfu} / \mathrm{g}$ at $11 \mathrm{~d}$ to $\sim 10^{8} \mathrm{cfu} / \mathrm{g}$ at $41 \mathrm{~d}$ (Figure 1B). The increase in PAB count during the warm room ripening stage is consistent with previous results for Grevé (Rehn et al., 2011) and Swiss-type cheeses (O'Sullivan et al., 2016). The count decreased slightly thereafter to $\sim 10^{7} \mathrm{cfu} / \mathrm{g}$ during cold storage $\left(4^{\circ} \mathrm{C}\right)$.

Although counts of NSLAB were very low at 1 and $11 \mathrm{~d}$ of ripening, their levels in all cheeses increased to $\sim 10^{8} \mathrm{cfu} / \mathrm{g}$ at $41 \mathrm{~d}$ of ripening and leveled off during further storage (Figure 1C); Sheehan et al. (2008) also observed a similar trend in Swiss-style cheeses. The NSLAB in cheese can originate from milk, processing equipment, or the processing environment, and counts are reported to be less than $10^{2} \mathrm{cfu} / \mathrm{g}$ in young cheese made under good sanitary conditions with high-quality milk (Steele et al., 2006). Pasteurization of milk drastically reduces the number of indigenous milk flora; however, some of these indigenous milk microorganisms can survive pasteurization and can grow during ripening of cheese (Grappin and Beuvier, 1997; Jordan and Cogan, 1999; Johnson, 2001; Quigley et al., 2013). Contrary to our results, O'Sullivan et al. (2016) observed high levels of NSLAB $\left(\sim 10^{6} \mathrm{cfu} / \mathrm{g}\right)$ at $1 \mathrm{~d}$ of ripening in Swiss-type cheese, and those authors speculated that they might have originated from the processing environment during cheese manufacture. The rapid increase in numbers of NSLAB during warm room ripening is attributed to elevated temperature $\left(23^{\circ} \mathrm{C}\right)$, which accelerates the metabolic activities of microorganisms (Beresford et al., 2001; De Filippis et al., 2016), and availability of substrates, such as sugars, nucleic acids and lactate, from metabolism of starters and their cell lysate (Steele et al., 2013; Ortakci et al., 2015). The NSLAB contribute to cheese maturation through production of enzymes and metabolites (Settanni and Moschetti, 2010). No significant effect of treatment was observed for mean counts of NSLAB, L. helveticus, and PAB during ripening (Table 1).

\section{Microbial Composition of Maasdam Cheese}

After DNA extraction, amplicons of the bacterial $16 \mathrm{~S}$ rRNA gene were generated by PCR. These amplicons were then subjected to next-generation sequencing, generating an average of 253,870 good-quality reads per sample. Alpha diversity was calculated for each
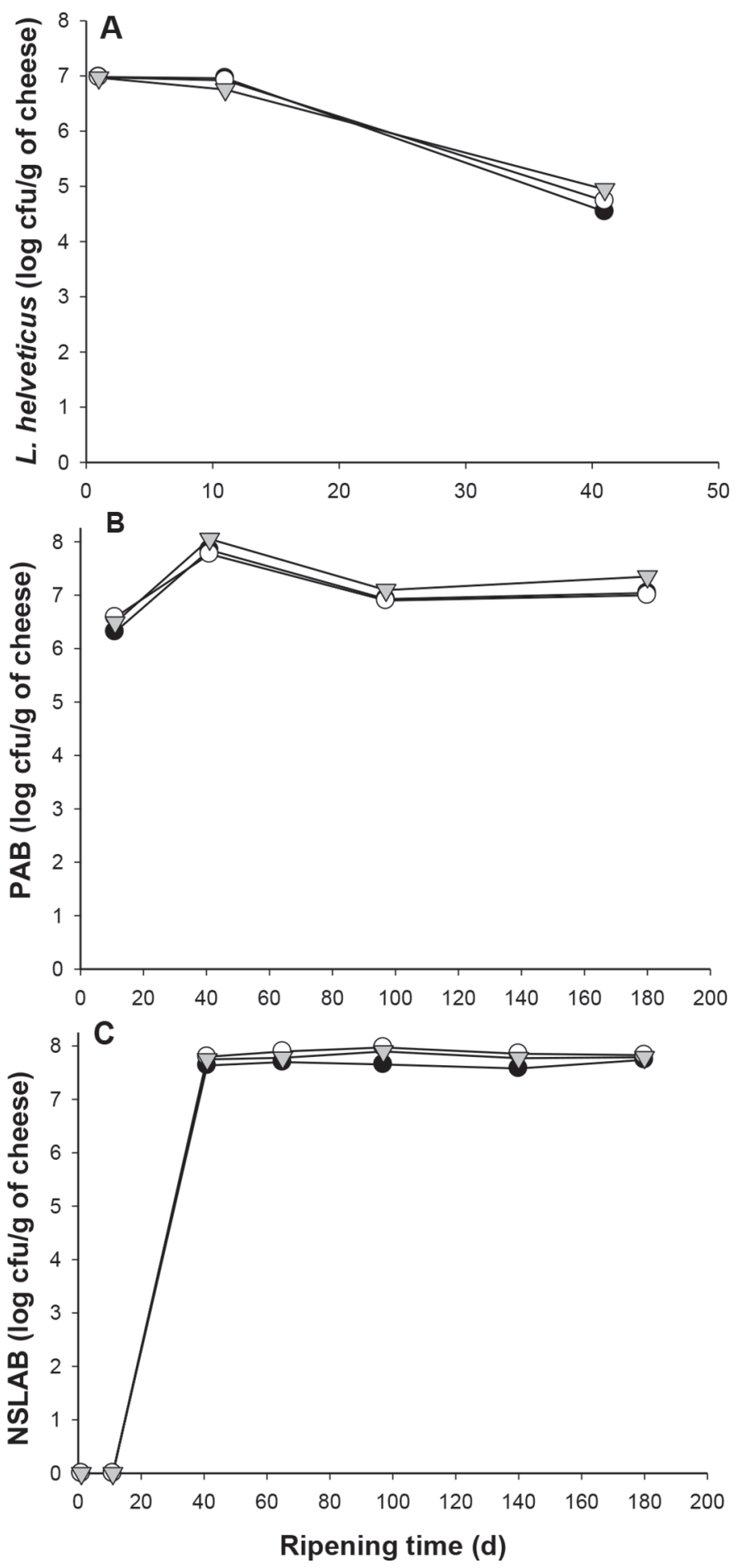

Figure 1. The effect of milk pretreatments on average count of (A) Lactobacillus helveticus, (B) propionic acid bacteria (PAB), and (C) nonstarter lactic acid bacteria (NSLAB) of Maasdam cheeses during ripening. Milk pretreatments were control $(\bullet)$; centrifugation $(\mathbf{\nabla})$; and centrifuged milk containing high heat-treated centrifugate $(\bigcirc)$. Data are means of data from 3 replicate trials. 
Table 1. Summary of the effects of treatment, ripening time, and their interactions on microbiology and shortchain carboxylic acids profile of Maasdam cheeses ${ }^{1}$

\begin{tabular}{llll}
\hline Parameter & Treatment & Time & $\begin{array}{l}\text { Interactive effect } \\
\text { (treatment } \times \text { time) }\end{array}$ \\
\hline Lactobacillus helveticus & NS $(0.71)$ & $* * *$ & NS $(0.37)$ \\
PAB & NS $(0.52)$ & $* * *$ & NS $(0.99)$ \\
NSLAB & NS $(0.37)$ & $* * *$ & NS $(0.99)$ \\
Acetic acid & NS $(0.49)$ & $* * *$ & NS $(0.99)$ \\
Propionic acid & NS $(0.55)$ & $* * *$ & NS $(1.00)$ \\
Butyric acid & $* * *$ & $* * *$ & NS $(0.28)$ \\
\hline
\end{tabular}

${ }^{1}$ Digits in parentheses after NS represent $P$-values; abbreviations: $\mathrm{PAB}=$ propionic acid bacteria; $\mathrm{NSLAB}=$ nonstarter lactic acid bacteria.

$* * * P<0.001$, NS $=P>0.05$.

sample to analyze species richness and diversity within each sample. Chao 1 values, which represented species richness, ranged from 16 to 65 , whereas the Shannon index ranged from 0.20 to 2.66. Analysis of these data revealed that the bacterial diversity fluctuated throughout the ripening process; however, an overall increase in diversity was observed, in contrast to a similar study conducted by O'Sullivan et al. (2015) in Swiss-type cheese with thermophilic starters Streptococcus thermophilus and Lactobacillus helveticus.

Differences in microbial taxa and shifts in relative abundance of the population were revealed between $\mathrm{CT}, \mathrm{CF}$, and CFHHT cheeses. Phylogenetic assignment of the sequences revealed presence of bacteria belonging to 7 phyla: Actinobacteria, Bacteroidetes, Cyanobacteria, Deferribacteres, Firmicutes, Proteobacteria, and Saccharibacteria. As expected, Firmicutes dominated across all samples, with relative abundance ranging between 78.72 and $99.96 \%$ in the CT cheeses, 67.83 to $99.86 \%$ in the CF cheeses, and 76.63 to $99.89 \%$ in the CFHHT cheeses. The second most abundant phylum was Actinobacteria, followed by Proteobacteria. In addition, a rapid increase in abundance of the bacteria belonging to Actinobacteria phylum can be observed after $41 \mathrm{~d}$ of ripening (after warm room stages) in all experimental cheese types.

Lactococcus, Lactobacillus, Propionibacterium, and Leuconostoc were the dominant genera of Maasdam cheese throughout ripening, accounting for more than 99\% relative abundance altogether (Figure 2). Before warm room ripening (i.e., until $11 \mathrm{~d}$ postproduction), the relative abundance of major microorganisms (at genus level) were similar between treatments; Lactococcus spp. (ranging from 86.8 to $94.5 \%$ ) dominated the curd population followed by Lactobacillus (4.8-12.4\%). Leuconostoc (0.15-0.4\%) and Propionibacterium (0.14$0.35 \%$ ) were detected in very small proportions during this period. These results were expected, as all these genera were added as starters or secondary starters at a similar proportion for all experimental cheeses.
In agreement with the results from the culture-based approach, the molecular approach also revealed major differences in microbial populations within the cheese matrix before and after warm room ripening. As expected, the relative abundance of Propionibacterium was higher after warm room ripening than before warm room ripening in all experimental cheeses. An increase in the level of PAB by $\sim 10^{1.5} \mathrm{cfu} / \mathrm{g}$ during warm room ripening was also observed in the culture-based method. Although the overall relative abundance of Lactococcus decreased after warm room ripening, it was still the most dominant microflora in all experimental cheeses; Lactobacillus and Propionibacterium were the second most abundant genera, followed by Leuconostoc. During maturation, in general, some lactic acid bacteria (LAB) within the starter cultures die off and their metabolites (e.g., lactate) and carbon sources from cell lysate (e.g., ribose) favor the growth of secondary starter, such as PAB and NSLAB (Ortakci et al., 2015). Moreover, the elevated temperature $\left(23^{\circ} \mathrm{C}\right)$ during warm room ripening accelerates the metabolic activity of microorganisms (Beresford et al., 2001; De Filippis et al., 2016).

Subtle differences were observed in the composition of dominant microflora (i.e., Lactococcus, Lactobacillus, Propionibacterium, and Leuconostoc) between treatments; however, the differences were not consistent throughout ripening. This suggests that milk centrifugation as well as incorporation of HHT centrifugate into cheese milk had minimal effect on the composition of major genera of Maasdam cheese, which is consistent with the results from selective media-based approach.

Apart from major microflora, many $(\sim 40)$ other genera were also detected; however, their relative abundances were very low, ranging from 0.04 to $0.95 \%$. Among these subdominant genera, Enterococcus, Stenotrophomonas, Paenibacillus, Pseudomonas, and Acinetobacter were detected in relatively higher abundance. The presence of Enterococcus was detected at all time points in CT and $\mathrm{CF}$ cheeses, and its population increased rapidly from $41 \mathrm{~d}$ of ripening. This genus was not detected 


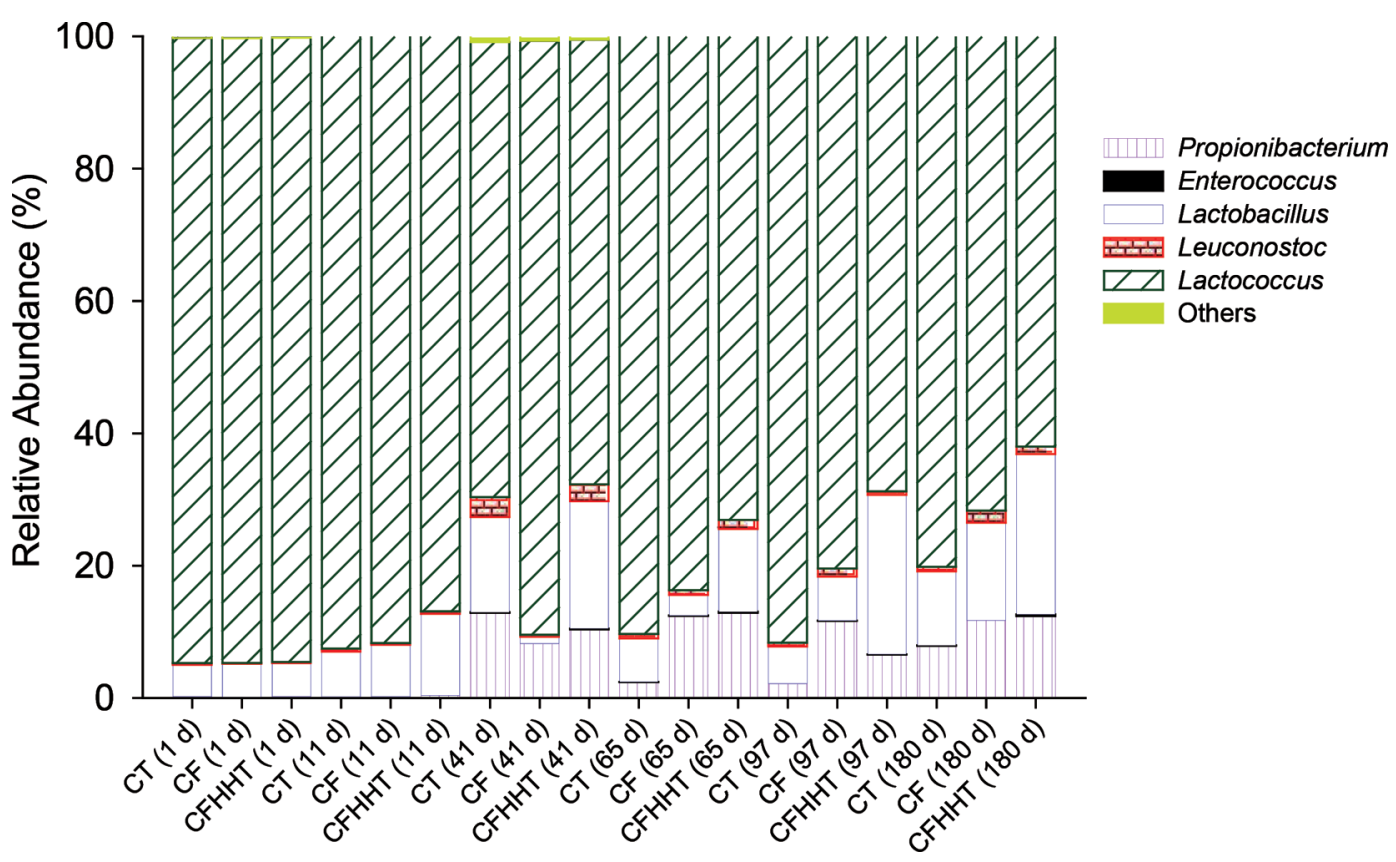

Figure 2. Relative abundance of bacteria at genus level within the 3 experimental cheese types during maturation: $\mathrm{CT}=$ control cheese, $\mathrm{CF}$ $=$ cheese made from centrifuged milk, CFHHT $=$ cheese made from centrifuged milk containing high heat-treated centrifugate. Data are means of data from 3 replicate trials. Color version available online.

in CFHHT cheeses at $1 \mathrm{~d}$ of ripening; however, it was detected thereafter. Enterococci have been previously isolated from traditional cheeses produced with raw or pasteurized milk and are considered to originate from bulk tank, milking machine, and processing equipment or the processing environment (Gelsomino et al., 2002; Nieto-Arribas et al., 2011). Although enterococci have shown a potential role in ripening and flavor development in some artisanal cheeses and cheeses made from raw milk (Beuvier et al., 1997; Beresford et al., 2001; Nieto-Arribas et al., 2011), the significance of the presence of this genus within Maasdam cheese matrix is not yet fully understood and requires further investigation.

Pseudomonas, Stenotrophomonas, and Acinetobacter were present in all experimental cheese types but in different proportions. The highest abundance of Pseudomonas was observed in CT cheeses, particularly at 1 , 11, and $97 \mathrm{~d}$ of ripening. Pseudomonas (psychrotrophic bacteria) have previously been isolated from cheese matrix (O'Sullivan et al., 2015), which can cause flavor and texture defects in cheese if they are present in high numbers (Champagne et al., 1994). Stenotrophomonas was present uniformly across the sample groups but not across time points. Although Acinetobacter has frequently been detected in several types of cheese, such as Camembert (Addis et al., 2001) and Swiss-style (O'Sullivan et al., 2015), its role on ripening of cheese is not fully understood.
Clostridium sensu stricto is a subset of the species of Clostridium that form a distinct cluster in the $16 \mathrm{~S}$ rRNA tree (cluster I; Gupta and Gao, 2009). Nearly all species within this genus produce butyric acid as a major fermentation product (Wiegel, 2009). Clostridium spp. associated with late blowing defect (LBD) of cheese, including Clostridium tyrobutyricum and Clostridium butyricum, also fall within this genus (Collins et al., 1994; Brändle et al., 2016). Although the overall percentage relative abundance of Clostridium sensu stricto was very low (below $0.05 \%$ ), the overall percentage relative abundance in CT cheeses (ranging between 0.00 and $0.02 \%$ throughout ripening) was relatively higher than those in CF (0.00 to 0.002\%) and CFHHT (0.00 to $0.003 \%$ ) cheeses; this may be explained by the removal of Clostridium spores from milk by centrifugation. It is well known that the centrifugation can remove more than 97\% of Clostridium spores from milk ( $\mathrm{Su}$ and Ingham, 2000; Te Giffel and Van Der Horst, 2004).

\section{Levels of Acetic, Propionic, and Butyric Acids}

Short-chain carboxylic acids contribute to the aroma profile of most cheese varieties (Kilcawley et al., 2001). Starter, secondary starter, and nonstarter bacteria present in the cheese matrix can produce short-chain volatile carboxylic acids, including propionic, acetic, and butyric acids. Propionic acid is one of the major 
products of lactate metabolism by PAB; hence, it was detected in all experimental cheeses at high levels (Figure $3 \mathrm{~A}$ ), particularly during warm room ripening, with a mean level of $\sim 50 \mathrm{mg} / \mathrm{kg}$ of cheese at $11 \mathrm{~d}$ (start of warm ripening) and $\sim 4,000 \mathrm{mg} / \mathrm{kg}$ of cheese at $41 \mathrm{~d}$ (end of warm room ripening). Similar trends have been reported in other studies (Huc et al., 2014; O'Sullivan et al., 2016). No significant effect of treatment was observed (Table 1). In Swiss-type cheese, propionic acid contributes to sweet or nutty notes characteristic of these varieties (Kilcawley et al., 2001).

The production of acetic acid followed a similar trend to that of propionic acid during ripening of cheese. Acetic acid in cheese can be formed from several pathways, including propionic acid fermentation by PAB, and metabolism of lactate and citrate by LAB (Sheehan et al., 2008; Huc et al., 2014). The mean level of acetic acid at 1 and $11 \mathrm{~d}$ of ripening was only $\sim 200 \mathrm{mg} / \mathrm{kg}$ of cheese; however, the level increased rapidly during warm room ripening to $\sim 2,200 \mathrm{mg} / \mathrm{kg}$ of cheese at $41 \mathrm{~d}$ (Figure 3B). The production of acetate in all experimental cheeses during warm room ripening is most likely due to activity of starter LAB, NSLAB, and PAB. No significant effect of treatment was observed (Table 1).

Significant effects of treatment and time were observed for mean levels of butyric acid during maturation (Table 1). The mean levels of butyric acid in CT cheeses were higher $(P<0.05)$ than in $\mathrm{CF}$ and CFHHT cheeses (Figure 3C), which coincided with the higher relative abundance of Clostridium sensu stricto in CT cheeses than CF and CFHHT cheeses, as revealed by highthroughput sequencing. Higher levels of butyric acid in the CT cheeses are most probably due to butyric acid fermentation by Clostridium, which may be removed during centrifugation in $\mathrm{CF}$ and CFHHT milks.

A high level of butyric acid can influence the flavor profile of cheese and may result in down-graded cheese. Some species of Clostridium produces carbon dioxide and hydrogen via butyric acid fermentation, which can impair the quality of eyes and also increase the risk of slits and crack formation in cheese (Sheehan, 2011; Gómez-Torres et al., 2015). The level of butyric acid in late-blown cheeses varies among studies; in semihard (Bogovič Matijašić et al., 2007) and Gouda cheese (Klijn et al., 1995), butyric acid contents higher than $200 \mathrm{mg} / \mathrm{kg}$ have been found to be associated with the LBD, and the severity of this defect was greater when the level of butyric acid was higher. However, it should be noted that butyric acid within the cheese matrix can also originate from lipolysis during ripening (Le Bourhis et al., 2007; Garde et al., 2012). Although the level of butyric acid was significantly higher in CT cheeses than $\mathrm{CF}$ and CFHHT cheeses, we did not observe LBD in the CT cheeses. In the current study, the level of butyric
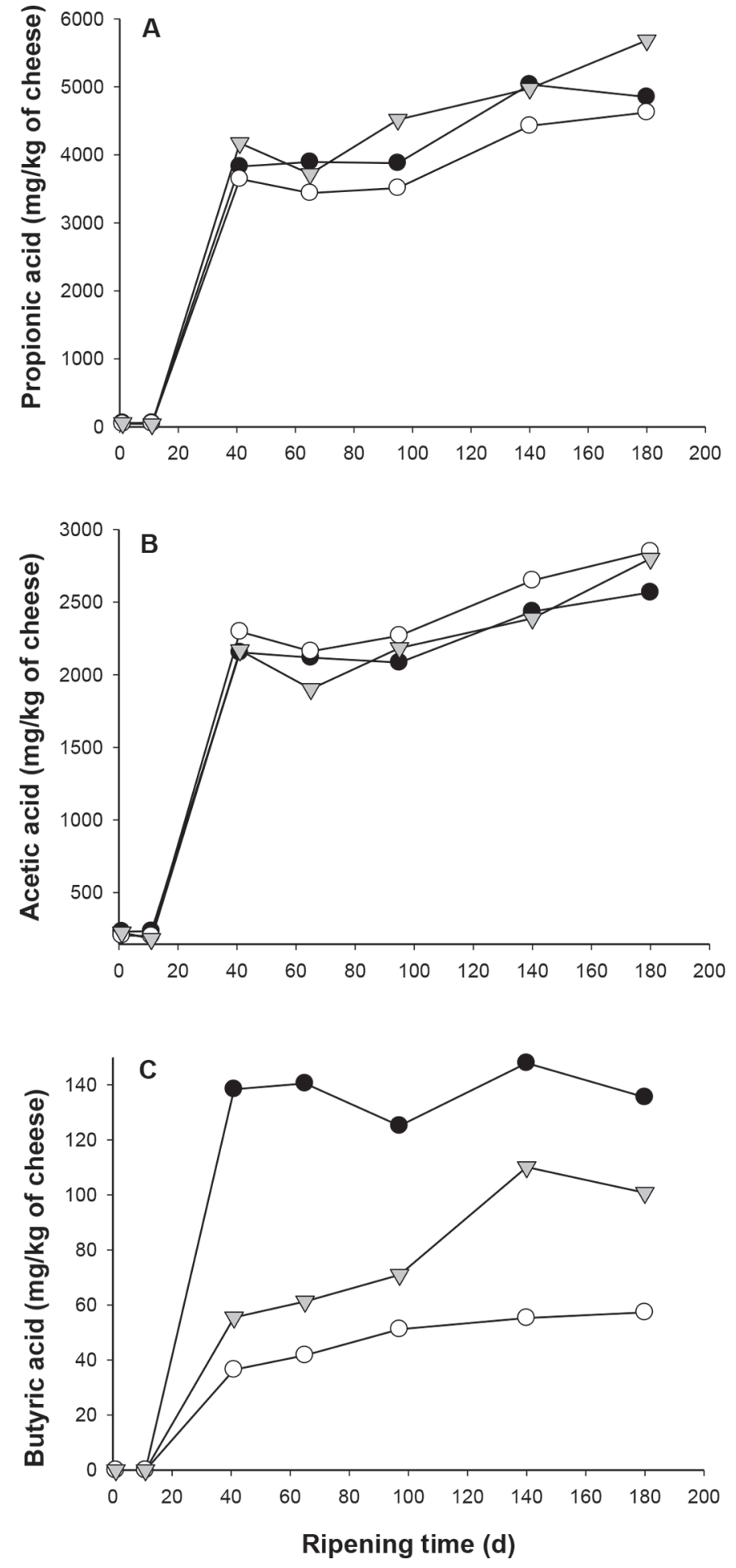

Figure 3. The effect of milk pretreatments on the mean level of (A) propionic acid, (B) acetic acid, and (C) butyric acid during ripening of Maasdam cheeses. Milk pretreatments were control $(\bullet)$; centrifugation $(\mathbf{\nabla})$; and centrifuged milk containing high heat-treated centrifugate (O). Data are means of data from 3 replicate trials. 
acid was below $200 \mathrm{mg} / \mathrm{kg}$ in all experimental cheeses over 6 mo of ripening. These results are in agreement with the studies of Le Bourhis et al. (2007) and Beuvier et al. (1997), who also observed butyric acid contents of less than $200 \mathrm{mg} / \mathrm{kg}$ in normal Swiss-type cheeses. The comparatively low level of butyric acid in the CT cheeses is most probably due to low levels of Clostridium spores in the cheese milk obtained from a local dairy company during spring-summer (May-July); during this period, contamination of milk with Clostridium is less likely, as the milk supply was from spring-calving herds fed on pasture grass rather than silage (the main source of clostridial spore contamination in milk; Sheehan, 2011). The levels of butyric acid between CF and CFHHT cheeses were not statistically different.

\section{Volatile Profile of Maasdam Cheese}

In total, 28 major volatile compounds were identified at $140 \mathrm{~d}$ of ripening, consisting of 8 ketones, 7 acids, 4 alcohols, 4 esters, 2 aldehydes, 2 sulfur compounds, and a hydrocarbon (Table 2). The volatile flavor compounds in cheese are the result of complex biochemical reaction during maturation, such as proteolysis, lipolysis, and glycolysis (McSweeney, 2004). The correct balance and concentration of a wide range of flavor compounds gives the characteristic flavor of different cheese varieties. Centrifugation of cheese milk and incorporation of HHT centrifugate into centrifuged milk had virtually no effect on the formation of volatile compounds at 140 $\mathrm{d}$ of ripening of Maasdam cheese. However, as expected, the mean relative abundance of butanoic acid (butyric acid) was lower $(P<0.05)$ in $\mathrm{CF}$ and CFHHT cheeses than in CT cheeses (Table 2), attributed to the removal of butyrate-fermenting Clostridium spores from cheese milk by the centrifugation process. Although butanoic acid at low levels contributes positively to the aroma of the cheese, it gives an undesirable rancid note at high concentration (Curioni and Bosset, 2002). Propionic and acetic acid were also detected in higher abundance in all experimental cheeses, as expected. The presence of hexanoic and octanoic acids within the experimental cheeses is attributed to lipolytic activity of enzymes (Delgado et al., 2010).

Only 2 aldehydes (i.e., benzaldehyde and 2-methylbutanal) were detected in all experimental cheeses, and these are derived from Phe and Ile, respectively (Yvon and Rijnen, 2001), via $\alpha$-keto acids by the transaminase pathway (Smit et al., 2005). Branched-chain aldehydes, including 2-methylbutanal, are generally detected in high levels in cheese containing PAB (Thierry et al., 2005) and are responsible for dark chocolate/ malty aroma notes (Singh et al., 2003; Bertuzzi et al.,
2017). Aldehydes are relatively unstable compounds and can further catabolize to other groups of volatile compounds, such as alcohols or carboxylic acids. It has been reported that 3-methylbutanal and 2-methylbutanal can oxidize to 3-methylbutanoic acid and 2-methylbutanoic acid, respectively, and these acids contribute to cheesy, sweaty, or rancid notes in cheese (Yvon and Rijnen, 2001). Alcohol dehydrogenase from lactic acid bacteria can convert 2-methylbutanal to 2-methyl1-butanol, which has fruity, waxy, or sweaty-fatty acid aroma notes (Singh et al., 2003).

Ketone flavor compounds, such as 2,3-butanedione (responsible for creamy/buttery aroma note), acetoin, and 2-butanone, are considered important volatile compounds in Maasdam cheese and are likely generated from metabolism of citrate by Lactococcus lactis and Leuconostoc spp. (Engels et al., 1997; Le Bars and Yvon, 2008). Detection of these ketone flavor compounds in all experimental cheeses at higher abundance is not surprising because Lactococcus and Leuconostoc spp. were added as starter culture, and these genera were also detected within the cheese matrix throughout ripening, as revealed by high-throughput sequencing. Interestingly, 2,3-pentanedione was only detected in $\mathrm{CF}$ and CFHHT cheeses, whereas 2-hexanone was only detected in CT cheeses; however, these compounds were detected in only 1 out of 3 trials. Pentane-2,3-dione has been suggested to be produced from intermediate of Ile metabolism (Imhof et al., 1995). Heptan-2-one, one of the important methyl ketones in Parmigiano-Reggiano cheese types (Qian and Reineccius, 2002), derived from the oxidation of octanoic acid, was also present in all experimental cheeses and likely contributes to cheesy or fruity aroma notes.

Ethanol and 2-butanol were the 2 most abundant alcohols detected in all experimental cheeses. Ethanol may be produced by the heterofermentative LAB present within the cheese matrix (Thierry et al., 2006). The abundance of ethanol and short-chain acids, such as propionic, butyric, and hexanoic acids, inevitably results in ethyl esters via esterification or alcoholysis from microbial activity (Hong et al., 2018). Ethanol is considered as the limiting factor for ethyl ester formation in different cheese types, including Swiss cheese (Thierry et al., 2006). Therefore, modulation of ethanol level can potentially alter the fruity flavor of Swiss (Thierry et al., 2006) and Camembert (Hong et al., 2017) cheeses.

Esters, especially ethyl esters, are responsible for fruity aroma notes in some cheese varieties, such as Parmesan and Swiss-type cheeses (Engels et al., 1997; Thierry et al., 2006). Ethyl propanoate was one of the most abundant esters in all experimental cheeses, 
in agreement with the results previously reported by other authors for cheeses containing PAB (Thierry et al., 2005; Thierry et al., 2006). Ethyl butanoate, propyl propanoate, and ethyl hexanoate were also detected.

Volatile sulfur compounds are considered to be an important contributor to the flavor of different cheese types, and these compounds are reported to have very low-odor threshold values (Martínez-Cuesta et al., 2013). Dimethyl sulfide (responsible for rotten cabbage/cheese/vegetative/sulfur aroma notes; Smit et al., 2005) and carbon disulfide were the 2 sulfur compounds present in all experimental cheeses at $140 \mathrm{~d}$ of ripening, which are considered important flavor compounds of Swiss cheese released from metabolic activity of PAB
(Adda et al., 1982). These sulfur-containing compounds are derived from the catabolism of sulfur AA (Met and Cys) by microorganisms during ripening (Smit et al., 2005; Liu et al., 2012).

Toluene was detected in all experimental cheeses and may originate from the degradation of $\beta$-carotene (Verzera et al., 2010; O'Callaghan et al., 2017). Some studies observed high levels of toluene in milk of cows fed on pasture grass (Villeneuve et al., 2013) and also in cheese made from milk of cows fed on pasture grass (O'Callaghan et al., 2017).

It is well known that heat treatment changes the flavor profile of milk through production of volatile compounds from proteins (e.g., sulfur compounds from heat

Table 2. Mean volatile compound peak areas from Maasdam cheese samples at $140 \mathrm{~d}$ of ripening ${ }^{1}$

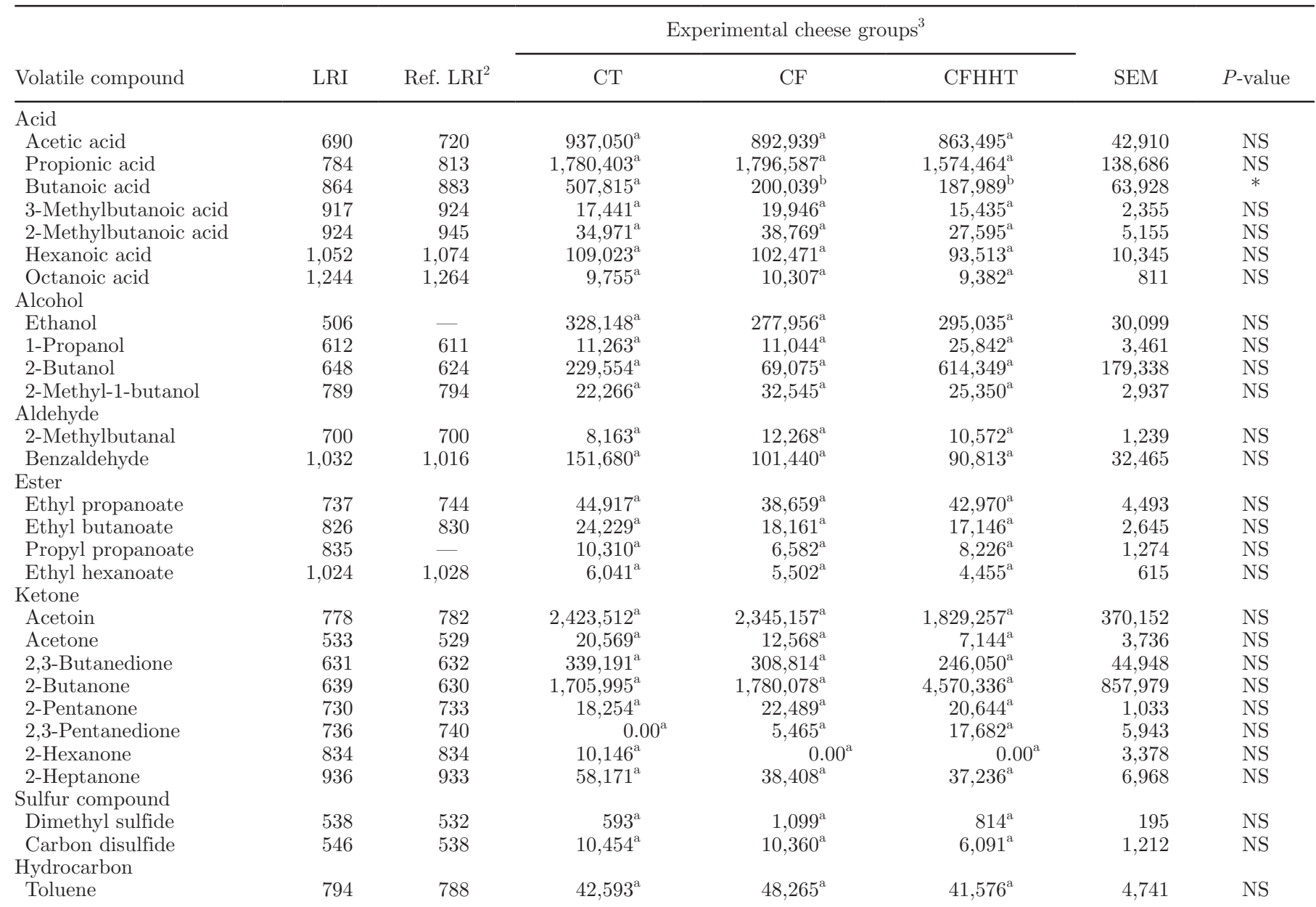

\footnotetext{
$\overline{\mathrm{a}, \mathrm{b}}$ Values within a row not sharing common superscripts differ significantly $(P<0.05)$; data presented are the means of data from 3 replicate trials.

${ }^{1} \mathrm{LRI}=$ linear retention index; Ref. LRI = reference linear retention index.

${ }^{2}$ Reference LRI for ethanol or propyl propanoate were not found; however, they have been identified correctly.

${ }^{3} \mathrm{CT}=$ control cheese; $\mathrm{CF}=$ cheese made from centrifuged milk; CFHHT $=$ cheese made from centrifuged milk containing high heat-treated centrifugate.

$* P<0.05, \mathrm{NS}=P>0.05$.
} 
denaturation of whey protein), carbohydrates (via the nonenzymatic browning reactions), and lipids (e.g., formation of methyl ketones, lactones, and aldehydes from degradation of milk fat; Calvo and de la Hoz, 1992). However, the volatile profile of cheese made from $\mathrm{CF}$ and CFHHT was not statistically different, suggesting that the VOC solely generated by the heat-treatment given to the centrifugate have minimal effects on the volatile profile of final cheese.

Overall, the treatments applied to the milk had minimal effect on the volatile profile of Maasdam cheese, except for butyric acid levels, suggesting that centrifugation is a suitable method for controlling undesirable butyric acid fermentation without significantly altering the other VOC in Maasdam cheese. The level of butyric acid in the current study was not high (below $200 \mathrm{mg} /$ $\mathrm{kg}$ of cheese) in all experimental cheeses, suggesting that the milk was contaminated by low levels of Clostridium spores. Although levels of Clostridium spores may be higher in milk supplies other than those studied, this would not influence the findings of the current study, as it was focused on the influence of the milk pretreatments (i.e., centrifugation and high heat treatment of centrifugate) on the microbial and volatile profile of the cheese and not on the influence of clostridia per se.

Based on the relative abundance of volatiles present in the current study and the previous study of Engels et al. (1997), acetoin, 2-butanone, propionic acid, acetic acid, 2,3-butanedione, and butyric acid (at low levels) can be considered as key aroma compounds of Maasdam cheese. Sensory analysis of the cheeses would complement the volatile results, and this could be the focus for future studies.

\section{CONCLUSIONS}

High-throughput sequencing in combination with a selective media-based approach revealed distinct differences in the composition of microbiota before and after warm room ripening. High-throughput sequencing facilitated a more detailed insight into the complexity of microbes within the Maasdam cheese matrix and revealed subtle changes in both dominant and subdominant microbiota between treatments. Interestingly, except for butyric acid, treatments applied had minimal effect on other VOC in the fully ripened Maasdam cheeses. Overall, high-throughput sequencing proved to be a useful method to profile the complex microbial population structure of Maasdam cheese during maturation; moreover, the centrifugation of milk before cheesemaking can potentially control the level of butyric acid in Maasdam cheese without significantly altering the levels of other VOC.

\section{ACKNOWLEDGMENTS}

This study was funded by the Dairy Levy Trust (Dublin, Ireland), Teagasc Walsh Fellowship program (Oak Park, Carlow, Ireland), and in part by Ornua (Dubin, Ireland). Prabin Lamichhane is currently in receipt of a Teagasc Walsh Fellowship (RMIS6259). The authors acknowledge Andrea Bertuzzi (Teagasc Food Research Centre, Cork, Ireland), for assistance with the statistical analysis of the data.

\section{REFERENCES}

Adda, J., J. C. Gripon, and L. Vassal. 1982. The chemistry of flavour and texture generation in cheese. Food Chem. 9:115-129. https:// doi.org/10.1016/0308-8146(82)90073-5.

Addis, E., G. H. Fleet, J. M. Cox, D. Kolak, and T. Leung. 2001. The growth, properties and interactions of yeasts and bacteria associated with the maturation of Camembert and blue-veined cheeses. Int. J. Food Microbiol. 69:25-36. https://doi.org/10.1016/S0168 $-1605(01) 00569-4$.

Alessandria, V., I. Ferrocino, F. De Filippis, M. Fontana, K. Rantsiou, D. Ercolini, and L. Cocolin. 2016. Microbiota of an Italian Granalike cheese during manufacture and ripening, unraveled by $16 \mathrm{~s}$ rRNA-based approaches. Appl. Environ. Microbiol. 82:3988-3995. https://doi.org/10.1128/AEM.00999-16.

Beresford, T. P., N. A. Fitzsimons, N. L. Brennan, and T. M. Cogan. 2001. Recent advances in cheese microbiology. Int. Dairy J. 11:259-274. https://doi.org/10.1016/S0958-6946(01)00056-5.

Bertuzzi, A. S., K. N. Kilcawley, J. J. Sheehan, M. G. O'Sullivan, D. Kennedy, P. L. H. McSweeney, and M. C. Rea. 2017. Use of smear bacteria and yeasts to modify flavour and appearance of Cheddar cheese. Int. Dairy J. 72:44-54. https://doi.org/10.1016/j.idairyj .2017.04.001.

Beuvier, E., K. Berthaud, S. Cegarra, A. Dasen, S. Pochet, S. Buchin, and G. Duboz. 1997. Ripening and quality of Swiss-type cheese made from raw, pasteurized or microfiltered milk. Int. Dairy J. 7:311-323. https://doi.org/10.1016/S0958-6946(97)00015-0.

Bogovič Matijašić, B., M. Koman Rajšp, B. Perko, and I. Rogelj. 2007. Inhibition of Clostridium tyrobutyricum in cheese by Lactobacillus gasseri. Int. Dairy J. 17:157-166. https://doi.org/10.1016/j.idairyj 2006.01.011.

Brändle, J., K. J. Domig, and W. Kneifel. 2016. Relevance and analysis of butyric acid producing clostridia in milk and cheese. Food Control 67:96-113. https://doi.org/10.1016/j.foodcont.2016.02 .038 .

Calvo, M. M., and L. de la Hoz. 1992. Flavour of heated milks. A review. Int. Dairy J. 2:69-81. https://doi.org/10.1016/0958 -6946(92)90001-3.

Champagne, C. P., R. R. Laing, D. Roy, A. A. Mafu, M. W. Griffiths, and C. White. 1994. Psychrotrophs in dairy products: Their effects and their control. Crit. Rev. Food Sci. Nutr. 34:1-30. https://doi .org/10.1080/104083994095276471.

Collins, M. D., P. A. Lawson, A. Willems, J. J. Cordoba, J. FernandezGarayzabal, P. Garcia, J. Cai, H. Hippe, and J. A. E. Farrow. 1994. The phylogeny of the genus Clostridium: Proposal of five new genera and eleven new species combinations. Int. J. Syst. Bacteriol. 44:812-826. https://doi.org/10.1099/00207713-44-4-812.

Curioni, P. M. G., and J. O. Bosset. 2002. Key odorants in various cheese types as determined by gas chromatography-olfactometry. Int. Dairy J. 12:959-984. https://doi.org/10.1016/S0958 -6946(02)00124-3.

De Filippis, F., A. Genovese, P. Ferranti, J. A. Gilbert, and D. Ercolini. 2016. Metatranscriptomics reveals temperature-driven functional changes in microbiome impacting cheese maturation rate. Sci. Rep. 6:21871. https://doi.org/10.1038/srep21871. 
Delgado, F. J., J. González-Crespo, R. Cava, J. García-Parra, and R. Ramírez. 2010. Characterisation by SPME-GC-MS of the volatile profile of a Spanish soft cheese P.D.O. Torta del Casar during ripening. Food Chem. 118:182-189. https://doi.org/10.1016/j foodchem.2009.04.081

Engels, W. J. M., R. Dekker, C. de Jong, R. Neeter, and S. Visser. 1997. A comparative study of volatile compounds in the watersoluble fraction of various types of ripened cheese. Int. Dairy J. 7:255-263. https://doi.org/10.1016/S0958-6946(97)00003-4.

Garde, S., M. Ávila, P. Gaya, R. Arias, and M. Nuñez. 2012. Sugars and organic acids in raw and pasteurized milk Manchego cheeses with different degrees of late blowing defect. Int. Dairy J. 25:8791. https://doi.org/10.1016/j.idairyj.2012.01.005.

Gelsomino, R., M. Vancanneyt, T. M. Cogan, S. Condon, and J. Swings. 2002. Source of enterococci in a farmhouse raw-milk cheese. Appl. Environ. Microbiol. 68:3560-3565. https://doi.org/ 10.1128/aem.68.7.3560-3565.2002.

Gómez-Torres, N., S. Garde, Á. Peirotén, and M. Ávila. 2015. Impact of Clostridium spp. on cheese characteristics: Microbiology, color, formation of volatile compounds and off-flavors. Food Control 56:186-194. https://doi.org/10.1016/j.foodcont.2015.03.025.

Grappin, R., and E. Beuvier. 1997. Possible implications of milk pasteurization on the manufacture and sensory quality of ripened cheese. Int. Dairy J. 7:751-761. https://doi.org/10.1016/S0958 -6946(98)00006-5.

Guarrasi, V., C. Sannino, M. Moschetti, A. Bonanno, A. Di Grigoli, and L. Settanni. 2017. The individual contribution of starter and non-starter lactic acid bacteria to the volatile organic compound composition of Caciocavallo Palermitano cheese. Int. J. Food Microbiol. 259:35-42. https://doi.org/10.1016/j.ijfoodmicro.2017.07 .022 .

Gupta, R. S., and B. Gao. 2009. Phylogenomic analyses of clostridia and identification of novel protein signatures that are specific to the genus Clostridium sensu stricto (cluster I). Int. J. Syst. Evol. Microbiol. 59:285-294. https://doi.org/10.1099/ijs.0.001792-0.

Hickey, C. D., M. A. E. Auty, M. G. Wilkinson, and J. J. Sheehan. 2017. Influence of process temperature and salting methods on starter and NSLAB growth and enzymatic activity during the ripening of cheeses produced with Streptococcus thermophilus and Lactobacillus helveticus. Int. Dairy J. 69:9-18. https://doi.org/10 .1016/j.idairyj.2016.12.015.

Hickey, C. D., V. Fallico, M. G. Wilkinson, and J. J. Sheehan. 2018. Redefining the effect of salt on thermophilic starter cell viability, culturability and metabolic activity in cheese. Food Microbiol. 69:219-231. https://doi.org/10.1016/j.fm.2017.08.015.

Hong, Q., X. M. Liu, F. Hang, J. X. Zhao, H. Zhang, and W. Chen. 2018. Screening of adjunct cultures and their application in ester formation in Camembert-type cheese. Food Microbiol. 70:33-41. https://doi.org/10.1016/j.fm.2017.08.009.

Hong, Q., G. Wang, Q. Zhang, F. Tian, L. Xiao-Ming, J. Zhao, Y.-Q. Chen, H. Zhang, and W. Chen. 2017. Enhancement of ester formation in Camembert cheese by addition of ethanol. Int. J. Dairy Technol. 70:220-227. https://doi.org/10.1111/1471-0307.12330.

Huc, D., S. Challois, M. Monziols, C. Michon, and F. Mariette. 2014. Spatial characterisation of eye-growing kinetics in semi-hard cheeses with propionic acid fermentation. Int. Dairy J. 39:259-269. https://doi.org/10.1016/j.idairyj.2014.06.010.

IBM Corp. 2016. IBM SPSS Statistics for Windows, Version 24.0. IBM Corp. Armonk, NY.

Imhof, R., H. Glättli, and J. O. Bosset. 1995. Volatile organic compounds produced by thermophilic and mesophilic single strain dairy starter cultures. Lebensm. Wiss. Technol. 28:78-86. https:// doi.org/10.1016/S0023-6438(95)80016-6.

Johnson, M. E. 2001. Cheese products. Pages 345-384 in Applied Dairy Microbiology. 2nd ed. E. H. Marth and J. L. Steele, ed. Marcel Dekker, New York, NY.

Johnson, M. E., and J. A. Lucey. 2006. Major technological advances and trends in cheese. J. Dairy Sci. 89:1174-1178. https://doi.org/ 10.3168/jds.S0022-0302(06)72186-5.
Jordan, K. N., and T. M. Cogan. 1999. Heat resistance of Lactobacillus spp. isolated from Cheddar cheese. Lett. Appl. Microbiol. 29:136140. https://doi.org/10.1046/j.1365-2672.1999.00607.x.

Kilcawley, K. N., M. G. Wilkinson, and P. F. Fox. 2001. A survey of lipolytic and glycolytic end-products in commercial Cheddar enzyme-modified cheese. J. Dairy Sci. 84:66-73. https://doi.org/ 10.3168/jds.S0022-0302(01)74453-0.

Klijn, N., F. F. Nieuwenhof, J. D. Hoolwerf, C. B. van der Waals, and A. H. Weerkamp. 1995. Identification of Clostridium tyrobutyricum as the causative agent of late blowing in cheese by species-specific PCR amplification. Appl. Environ. Microbiol. 61:2919-2924.

Lamichhane, P., A. L. Kelly, and J. J. Sheehan. 2018. Effect of milk centrifugation and incorporation of high heat-treated centrifugate on composition, texture and ripening characteristics of Maasdam cheese. J. Dairy Sci. 101:5724-5737. https://doi.org/10.3168/jds 2017-14178

Le Bars, D., and M. Yvon. 2008. Formation of diacetyl and acetoin by Lactococcus lactis via aspartate catabolism. J. Appl. Microbiol. 104:171-177. https://doi.org/11.1111/j.1365-2672.2007.03539.x.

Le Bourhis, A.-G., J. Doré, J.-P. Carlier, J.-F. Chamba, M.-R. Popoff, and J.-L. Tholozan. 2007. Contribution of C. beijerinckii and $C$. sporogenes in association with $C$. tyrobutyricum to the butyric fermentation in Emmental type cheese. Int. J. Food Microbiol. 113:154-163. https://doi.org/10.1016/j.ijfoodmicro.2006.06.027.

Liu, M., C. Prakash, A. Nauta, R. J. Siezen, and C. Francke. 2012 Computational analysis of cysteine and methionine metabolism and its regulation in dairy starter and related bacteria. J. Bacteriol. 194:3522-3533. https://doi.org/10.1128/JB.06816-11.

Martínez-Cuesta, M. C., C. Peláez, and T. Requena. 2013. Methionine metabolism: Major pathways and enzymes involved and strategies for control and diversification of volatile sulfur compounds in cheese. Crit. Rev. Food Sci. Nutr. 53:366-385. https://doi.org/10 $.1080 / 10408398.2010 .536918$.

McSweeney, P. L. H. 2004. Biochemistry of cheese ripening. Int. J. Dairy Technol. 57:127-144. https://doi.org/10.1111/j.1471-0307 .2004.00147.x.

Montel, M.-C., S. Buchin, A. Mallet, C. Delbes-Paus, D. A. Vuitton, N. Desmasures, and F. Berthier. 2014. Traditional cheeses: Rich and diverse microbiota with associated benefits. Int. J. Food Microbiol. 177:136-154. https://doi.org/10.1016/j.ijfoodmicro.2014 .02 .019 .

Nieto-Arribas, P., S. Seseña, J. M. Poveda, R. Chicón, L. Cabezas, and L. Palop. 2011. Enterococcus populations in artisanal Manchego cheese: Biodiversity, technological and safety aspects. Food Microbiol. 28:891-899. https://doi.org/10.1016/j.fm.2010.12.005.

O'Callaghan, T. F., D. T. Mannion, D. Hennessy, S. McAuliffe, M. G. O'Sullivan, N. Leeuwendaal, T. P. Beresford, P. Dillon, K. N. Kilcawley, J. J. Sheehan, R. P. Ross, and C. Stanton. 2017. Effect of pasture versus indoor feeding systems on quality characteristics, nutritional composition, and sensory and volatile properties of fullfat Cheddar cheese. J. Dairy Sci. 100:6053-6073. https://doi.org/ 10.3168/jds.2016-12508.

O'Sullivan, D. J., P. D. Cotter, O. O'Sullivan, L. Giblin, P. L. H. McSweeney, and J. J. Sheehan. 2015. Temporal and spatial differences in microbial composition during the manufacture of a continentaltype cheese. Appl. Environ. Microbiol. 81:2525-2533. https://doi .org/10.1128/AEM.04054-14.

O'Sullivan, D. J., P. L. H. McSweeney, P. D. Cotter, L. Giblin, and J. J. Sheehan. 2016. Compromised Lactobacillus helveticus starter activity in the presence of facultative heterofermentative Lactobacillus casei DPC6987 results in atypical eye formation in Swisstype cheese. J. Dairy Sci. 99:2625-2640. https://doi.org/10.3168/ jds.2015-10503.

Ortakci, F., J. R. Broadbent, C. J. Oberg, and D. J. McMahon. 2015. Late blowing of Cheddar cheese induced by accelerated ripening and ribose and galactose supplementation in presence of a novel obligatory heterofermentative nonstarter Lactobacillus wasatchensis. J. Dairy Sci. 98:7460-7472. https://doi.org/10.3168/jds.2015 $-9468$. 
Qian, M., and G. Reineccius. 2002. Identification of aroma compounds in Parmigiano-Reggiano cheese by gas chromatography/olfactometry. J. Dairy Sci. 85:1362-1369. https://doi.org/10.3168/jds.S0022 -0302(02)74202-1.

Quigley, L., R. McCarthy, O. O'Sullivan, T. P. Beresford, G. F. Fitzgerald, R. P. Ross, C. Stanton, and P. D. Cotter. 2013. The microbial content of raw and pasteurized cow milk as determined by molecular approaches. J. Dairy Sci. 96:4928-4937. https://doi .org/10.3168/jds.2013-6688.

Quigley, L., O. O'Sullivan, T. P. Beresford, R. P. Ross, G. F. Fitzgerald, and P. D. Cotter. 2012. High-throughput sequencing for detection of subpopulations of bacteria not previously associated with artisanal cheeses. Appl. Environ. Microbiol. 78:5717-5723. https://doi.org/10.1128/AEM.00918-12.

Rehn, U., F. K. Vogensen, S. E. Persson, K. Hallin Saedén, B. F. Nilsson, and Y. Ardö. 2011. Influence of microflora on texture and contents of amino acids, organic acids, and volatiles in semi-hard cheese made with DL-starter and propionibacteria. J. Dairy Sci. 94:1098-1111. https://doi.org/10.3168/jds.2010-3146.

Ruggirello, M., P. Dolci, and L. Cocolin. 2014. Detection and viability of Lactococcus lactis throughout cheese ripening. PLoS One 9:e114280. https://doi.org/10.1371/journal.pone.0114280.

SAS Institute Inc. 2011. SAS/STAT 9.3 User's Guide. SAS Institute Inc., Cary, NC.

Settanni, L., and G. Moschetti. 2010. Non-starter lactic acid bacteria used to improve cheese quality and provide health benefits. Food Microbiol. 27:691-697. https://doi.org/10.1016/j.fm.2010.05.023.

Sheehan, J. J. 2011. Avoidance of gas blowing. Pages 661-666 in Encyclopedia of Dairy Sciences. Vol. 1. J. W. Fuquay, P. F. Fox, and P. L. H. McSweeney, ed. Elsevier, London, UK.

Sheehan, J. J. 2013. Milk quality and cheese diversification. Ir. J. Agric. Food Res. 52:243-253.

Sheehan, J. J., M. G. Wilkinson, and P. L. H. McSweeney. 2008. Influence of processing and ripening parameters on starter, non-starter and propionic acid bacteria and on the ripening characteristics of semi-hard cheeses. Int. Dairy J. 18:905-917. https://doi.org/10 .1016/j.idairyj.2007.11.024.

Singh, T. K., M. A. Drake, and K. R. Cadwallader. 2003. Flavor of Cheddar cheese: A chemical and sensory perspective. Compr. Rev. Food Sci. Food Saf. 2:166-189. https://doi.org/10.1111/j.1541 $-4337.2003 . t b 00021 . x$

Smit, G., B. A. Smit, and W. J. M. Engels. 2005. Flavour formation by lactic acid bacteria and biochemical flavour profiling of cheese products. FEMS Microbiol. Rev. 29:591-610. https://doi.org/10 .1016/j.femsre.2005.04.002.

Steele, J., J. Broadbent, and J. Kok. 2013. Perspectives on the contribution of lactic acid bacteria to cheese flavor development. Curr. Opin. Biotechnol. 24:135-141. https://doi.org/10.1016/j.copbio .2012.12.001.
Steele, J. L., M. F. Budinich, H. Cai, S. C. Curtis, and J. R. Broadbent. 2006. Diversity and metabolic activity of Lactobacillus casei in ripening Cheddar cheese. Aust. J. Dairy Technol. 61:53.

Su, Y.-C., and S. C. Ingham. 2000. Influence of milk centrifugation, brining and ripening conditions in preventing gas formation by Clostridium spp. in Gouda cheese. Int. J. Food Microbiol. 54:147154. https://doi.org/10.1016/S0168-1605(99)00199-3.

Te Giffel, M. C., and H. C. Van Der Horst. 2004. Comparison between bactofugation and microfiltration regarding efficiency of somatic cell and bacteria removal. Bull. Int. Dairy Fed. 389:49-53.

Thierry, A., M.-B. Maillard, R. Richoux, J.-R. Kerjean, and S. Lortal. 2005. Propionibacterium freudenreichii strains quantitatively affect production of volatile compounds in Swiss cheese. Lait 85:57-74. https://doi.org/10.1051/lait:2004036.

Thierry, A., M.-B. Maillard, R. Richoux, and S. Lortal. 2006. Ethyl ester formation is enhanced by ethanol addition in mini Swiss cheese with and without added propionibacteria. J. Agric. Food Chem. 54:6819-6824. https://doi.org/10.1021/jf060673m.

Vandendool, H., and P. D. Kratz. 1963. A generalization of the retention index system including linear temperature programmed gas - liquid partition chromatography. J. Chromatogr. 11:463-471. https://doi.org/10.1016/S0021-9673(01)80947-X.

Verzera, A., C. Condurso, M. Ziino, V. Romeo, M. Todaro, F. Conte, and G. Dima. 2010. Free fatty acids and other volatile compounds for the characterisation of "Vastedda della valle del Belìce" cheese. CYTA J. Food 8:237-243. https://doi.org/10.1080/ 19476330903450282.

Villeneuve, M. P., Y. Lebeuf, R. Gervais, G. F. Tremblay, J. C. Vuillemard, J. Fortin, and P. Y. Chouinard. 2013. Milk volatile organic compounds and fatty acid profile in cows fed timothy as hay, pasture, or silage. J. Dairy Sci. 96:7181-7194. https://doi.org/10 .3168/jds.2013-6785.

Wehrens, R., G. Weingart, and F. Mattivi. 2014. metaMS: An opensource pipeline for GC-MS-based untargeted metabolomics. J. Chromatogr. B Analyt. Technol. Biomed. Life Sci. 966:109-116. https://doi.org/10.1016/j.jchromb.2014.02.051.

White, S. R., J. R. Broadbent, C. J. Oberg, and D. J. McMahon. 2003. Effect of Lactobacillus helveticus and Propionibacterium freudenrichii ssp. shermanii combinations on propensity for split defect in Swiss cheese. J. Dairy Sci. 86:719-727. https://doi.org/10.3168/jds .S0022-0302(03)73652-2.

Wiegel, J. 2009. Family I. Clostridiaceae Pribram 1933, 90 ${ }^{\mathrm{AL}}$. Pages 736-738 in Bergey's Manual of Systematic Bacteriology. Vol. 2. 3rd ed. P. De Vos, G. M. Garrity, D. Jones, N. R. Krieg, W. Ludwig, F. A. Rainey, K. H. Schleifer, and W. B. Whitman, ed. Springer, New York, NY.

Yvon, M., and L. Rijnen. 2001. Cheese flavour formation by amino acid catabolism. Int. Dairy J. 11:185-201. https://doi.org/10 $.1016 /$ S0958-6946(01)00049-8. 